Fernando Felício Pachi Filho

Faculdade de Tecnologia Termomecânica (FTT) e da Universidade Paulista (UNIP).

Rafael Bellan

Rodrigues de Souza

Professor do Departamento de Comunicação e do Programa de Pós-Graduação em Comunicação e Territorialidades da Universidade Federal do Espírito Santo (UFES).

João Augusto Moliani

Professor do Departamento de Comunicação e Linguagens da Universidade Tecnológica Federal do Paraná (UTFPR).

\section{Os conceitos diferenciados de comunicação e jornalismo alternativos e 0 mapeamento da produção acadêmica brasileira recente}

\section{The differentiated concepts of alternative communication and alternative journalism and the mapping of recent brazilian academic production} Los conceptos diferenciales de comunicación y periodismo alternativos y el mapeo de la producción académica brasileña reciente 


\section{RESUMO}

Neste estudo, procuramos destacar os conceitos apresentados em artigos científicos para caracterizar a comunicação e o jornalismo alternativos. A busca dos dados foi feita por intermédio de pesquisa bibliográfica por meio de palavras-chave em bases de dados da Intercom, Compós e lbercom. Também foram identificados artigos veiculados em revistas científicas A2 e B1 que abordassem o tema para constituir o corpus do trabalho. Após a filtragem dos dados, os artigos foram catalogados considerando os conceitos trabalhados pelos próprios autores. A análise das referências utilizadas por eles possibilitou identificar as linhas teóricas que definem o conceito de alternativo na comunicação. Ainda foi possível mapear as regiões do país e as instituições onde essa produção é mais significativa. Os resultados indicam que as pesquisas nessa área adotam diferenças conceituais no tratamento da comunicação alternativa e do jornalismo alternativo, definidas com base na interpretação feita à luz da história dessas práticas no Brasil.

Palavras-chave: Comunicação alternativa. Comunicação e Trabalho. Jornalismo alternativo. Conceitos de alternativo. CPAC.

\section{ABSTRACT}

In this study, we sought to highlight the concepts presented in scientific articles to characterize alternative communication and journalism. The search of the data was done through bibliographic research through keywords in databases of Intercom, Compós and Ibercom. We also identified articles published in scientific journals qualis $\mathrm{A} 2$ and $\mathrm{B} 1$ that addressed the theme to constitute the corpus of work. After filtering the data, the articles were cataloged considering the concepts worked by the authors themselves. The analysis of the references used by them made it possible to identify the theoretical lines that define the concept of alternative in communication. It was also possible to map the regions of the country and the institutions where this production is most significant. The results indicate that research in this area adopts conceptual differences in the treatment of alternative communication and alternative journalism, defined based on the interpretation made based on the history of these practices in Brazil.

Keywords: Alternative communication. Communication and Work. Alternative journalism. Concepts of alternative. CPAC.

\section{RESUMÉN}

En este estudio, buscamos resaltar los conceptos presentados en artículos científicos para caracterizar la comunicación y el periodismo alternativos. La búsqueda de los datos se realizó a través de la investigación bibliográfica por lo intermedio de palabras clave en bases de datos de Intercom, Compós e lbercom. También identificamos los artículos publicados en las revistas científicas qualis $\mathrm{A} 2$ y $\mathrm{B} 1$ que abordaban el tema que constituye el cuerpo de trabajo. Después de filtrar los datos, los artículos fueron catalogados considerando los conceptos trabajados por los propios autores. El análisis de las referencias utilizadas por ellos permitió identificar las líneas teóricas que definen el concepto de alternativa en la comunicación. Todavía fue posible mapear las regiones del país y las instituciones donde esta producción es más significativa. Los resultados indican que la investigación en esta área adopta diferencias conceptuales en el tratamiento de la comunicación alternativa y el periodismo alternativo, definidas en base a la interpretación hecha a la luz de la historia de estas prácticas en Brasil.

Palabras clave: Comunicación alternativa. Comunicación y trabajo. Periodismo alternativo. Conceptos de lo alternativo. CPAC.

* Esta é uma versão revisada e ampliada de trabalho apresentado no Pensacom 2016 referente à pesquisa "As relações de comunicação e as condições de produção no trabalho de jornalistas em arranjos econômicos alternativos às corporações de mídia", realizada pelo Centro de Pesquisa em Comunicação e Trabalho (CPCT). (FIGARO, 2018)

Submissão: 7-8-2017

Decisão editorial: 17-4-2019 


\section{Introdução}

O termo alternativo (a), em sua dicionarização na língua portuguesa,' expressa diferentes sentidos para o que é alternativo: pode ser desde aquilo que se faz ou o que ocorre com alternação ou alternância, tendo o efeito de substituir algo que vinha sendo feito com função igual ou semelhante à que estava sendo feita originalmente, mas que não pode ser realizadas simultaneamente; ou significar a solução para algo que parece não estar adequado, seja um remédio ou um caminho, podendo haver uma ou mais possibilidades de escolhas facultadas a alguém. Alternativo significa ainda a proposição de substituição de um sistema todo, seja cultural, técnico ou político, bem como, uma "opção fora das instituições, costumes, valores e ideias convencionais" em um dado momento histórico ou pode representar apenas determinada parte, diferenciada, dos componentes desse sistema/sociedade.

Partindo desses conceitos, buscamos identificar como a comunicação alternativa - e mais especificamente o jornalismo alternativo - são compreendidos nos estudos comunicacionais, com o objetivo de caracterizar o que seja a imprensa alternativa nos dias

A pesquisa foi feita nos dicionários Houaiss e Michaelis em suas versões on-line disponíveis no portal www.uol.com.br. 
atuais. O primeiro passo foi encontrar artigos científicos que abordassem o tema da comunicação/jornalismo alternativos, o que foi feito a partir da busca em anais eletrônicos dos congressos da Sociedade Brasileira de Estudos Interdisciplinares da Comunicação (Intercom), da Associação Nacional dos Programas de Pós-Graduação em Comunicação (Compós) e da Associação Iberoamericana de Comunicação (Ibercom)² por meio das palavras-chave "comunicação alternativa", "imprensa alternativa" e "jornalismo alternativo". A seguir, foi feita a verificação da seleção utilizando apenas as palavras "alternativa" e "alternativo"3 filtrando os que não se referiam diretamente ao objetivo de estudo e agregando textos que não foram contemplados na busca anterior.

Também foi feita uma pesquisa em revistas acadêmicas ${ }^{4}$ com Qualis A2 e B1, tendo como referência

2 Dos congressos da Intercom foram separados 67 textos, sem distinção entre encontros regionais ou nacionais. Do Ibercom/2015 selecionamos seis trabalhos e, dos eventos, da Compós mais dois artigos.

3 Para exemplificar a pesquisa feita no portal da Intercom, no Portcom, com a expressão "comunicação alternativa" retornou 27 textos. O mesmo procedimento foi feito com "imprensa alternativa" e retornou outros 25 artigos. Com "jornalismo alternativo" foram 12. A seguir eram feitas novas pesquisas com as palavras "alternativa" e "alternativo", da qual retornaram 132 e 28 resultados, respectivamente. Esses resultados eram confrontados para identificar possíveis textos que não foram apanhados na busca original e depois eram eliminadas as duplicidades. O procedimento se repetiu com a base de dados dos demais congressos.

4 Para esta pesquisa foram selecionados 19 textos veiculados nas revistas Animus (UFSM), Brazilian Journalism Research (SBPJor), Comunicação e Sociedade (UMESP), Conexão (UCS), Contemporânea (UFBA), Contracampo (UFF), E-Compós (Compós), Em Questão (UFRGS), Estudos em Jornalismo e Mídia (UFSC), Famecos (PUCRS), Fronteiras (UNISINOS), Galáxia (PUCSP), Intercom (Intercom), Logos (UERJ), Matrizes (USP) e Rumores (USP) 
a classificação utilizada pela Capes $^{5}$ e os anos de 2011 a 2016. A partir da análise dos sumários identificamos títulos que indicassem proximidade com o nosso objeto e desses eram consultadas as palavras-chave e o resumo. Como alguns dos artigos já haviam sido publicados em anais e estavam catalogados, selecionamos apenas os que não estavam em duplicidade. Ao final contabilizamos um corpus de 94 artigos.

Após a definição do corpus, buscamos separar os trabalhos que tratavam especificamente de imprensa e/ou jornalismo alternativos diferenciando-os de outros processos comunicacionais não-jornalísticos. Essa divisão, no entanto, é apenas referencial para fins deste estudo, visto que muitos dos textos perpassam ambos os caminhos. Ela é significativa para podermos identificar quais são os autores de referência adotados por quem pesquisa jornalismo alternativo e por quem pesquisa comunicação alternativa.

\section{Jornalismo/imprensa alternativos}

A categoria relacionada ao alternativo em uma perspectiva mais diretamente ligada ao jornalismo ficou composta por 43 textos com diferentes abordagens e dimensões do que se considera imprensa e/ou jornalismo alternativos e que formam variados conjuntos de trabalhos. (ver Gráfico 1)

O primeiro deles guarda semelhança com o que Otre (2015) apontou como sendo "comunicação popular e alternativa" e "jornalismo popular alternativo". Observamos que os artigos que foram enquadrados nesse grupo tratam de modos de informar - em especial a

5 Disponível em: https://sucupira.capes.gov.br/sucupira/ public/consultas/coleta/veiculoPublicacaoQualis/ listaConsultaGeralPeriodicos.jsf 
Gráfico 1: Panorama das pesquisas sobre o alternativo relacionado à produção jornalística.
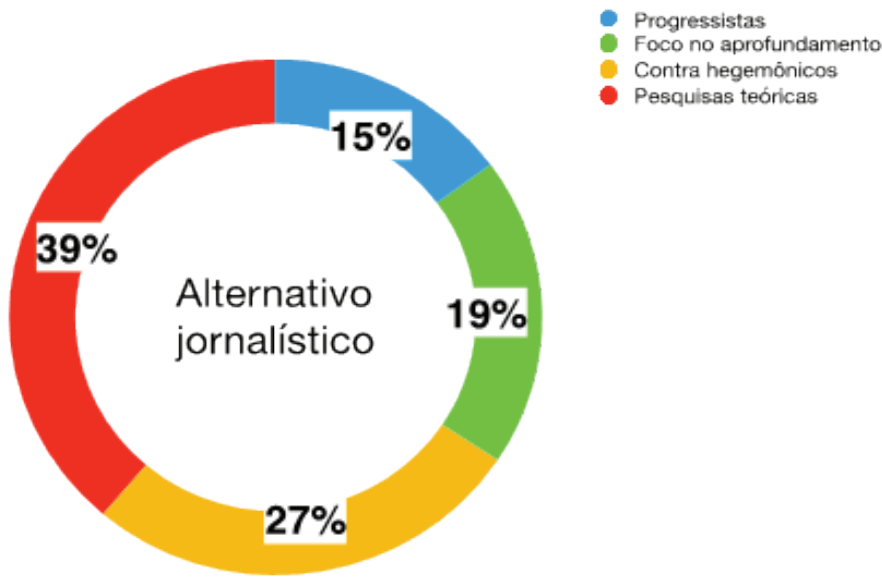

Fonte: Elaboração dos autores.

partir da internet e de forma mais personalizada - um outro lado da notícia veiculada pela imprensa hegemônica. É uma maneira de comunicar que se contrapõe aos discursos dos veículos tradicionais e comerciais e feita por veículos que se colocam ao lado do poder político estabelecido com o qual se identificam. Diante de questões polêmicas se ombreiam com esse poder e buscam defender as ações adotadas por ele.

Para Prudêncio et al. (2010), o resultado dessa forma de alternativo é, normalmente, "um produto com as mesmas características criticadas pelos grupos sociais em relação à grande mídia, como a supressão de informação, ausência de pluralidade e visão parcial" e se voltando para a defesa da ideologia dos grupos e movimentos que os financiam. Enquadram-se nesse perfil os veículos com abordagens mais "progressistas";;

6 Dos 43 estudos que tinham como foco o jornalismo alternativo nove tinham esse perfil de abordagem. 
Um segundo grupo apresenta o alternativo como possibilidade de resposta ou uma escolha para além da imprensa comercial hegemônica, ou seja, eles particularizam as demandas sociais com "foco no aprofundamento" e não afrontavam diretamente a hegemonia da mídia. Os meios estudados nos artigos abordam assuntos diretamente relacionados a uma causa ou grupo e que consideram não serem tratados adequadamente pela imprensa convencional. Posicionam-se de modo mais complementar que alternativo à mídia tradicional. Seu foco está voltado para os objetivos particularizados, mantendo-se fiéis ao seu escopo principal de aprofundar certas discussões e olhares e são voltados para segmentos mais específicos da sociedade como gays, negros, mulheres e meio ambiente, por exemplo.?

O terceiro grupo é o que representa o conceito mais difundido de jornalismo alternativo e que significa uma opção fora das instituições, costumes, valores e ideias convencionais, ou seja, são os "contra hegemônicos" que se contrapõem ao status quo. Nesse grupo entram os estudos de veículos e ações que, tanto de forma humorística quanto mais sóbria, se posicionaram contra o regime militar e os governos que o sucederam imediatamente após a abertura política ${ }^{8}$.

Encontramos ainda um quarto conjunto formado por estudos que se dedicam a esclarecer esse subcampo a partir de "pesquisas teóricas", fugindo da tradicional análise dos meios?. São textos que buscam apresentar uma alternativa ao jornalismo alternativo

\footnotetext{
7 Aqui foram contabilizados 12 textos que abordavam essa particularização das demandas de segmentos da sociedade.

8 Havia 14 estudos que abordavam mais diretamente a contestação ao regime militar.

9 As questões mais teóricas sobre jornalismo alternativo foram abordadas em oito textos.
} 
(PRUDÊNClO et al, 2010) ou se debruçam sobre os caminhos que se apresentam a esse jornalismo (BARBOSA, 2011; POSSEBON; NOGUEIRA, 2010).

O autor mais citados nessa categoria, que mantêm relação direta com o jornalismo, é Bernardo Kucinski com 19 citações em 18 trabalhos. Ele é adotado quase que exclusivamente pela sua obra Jornalistas e Revolucionários: nos tempos da imprensa alternativa. Quem também aparece de modo significativo é Cicilia Maria Khroling Peruzzo, que foi citada em 11 trabalhos, mas com 18 citações de diferentes obras. Outros autores de referência para quem escreve sobre jornalismo alternativo são Rivaldo Chinem, Ciro Marcondes Filho e Perseu Abramo ${ }^{10}$. (ver Tabela 1) Comunicação popular, alternativa e comunitária

A segunda categoria na qual classificamos os autores de referência é a que trata da comunicação popular, alternativa e comunitária que envolve um processo comunicacional que suplanta o jornalístico e abarca outras questões para além do objetivo informacional. Otre (2015), tendo como referência as pesquisas de Cicilia Peruzzo, chamou de "comunicação popular e comunitária" e de "comunicação popular, alternativa e comunitária". Em geral, os textos abordam experiências contemporâneas de comunicação que estão relacionadas a movimentos sociais e às tecnologias de informação e comunicação, além de se voltarem mais para experiências em comunidades específicas.

Nessa categoria, com 51 textos, foram identificados cinco perfis de estudos. O primeiro deles é dos textos que se referem à comunicação alternativa

\footnotetext{
10 Também aparecem como referência nos artigos, mas em menor volume, Venício Lima, Denise Cogo, Perseu Abramo e Dênis de Moraes.
} 
Tabela 1: Relação dos autores com maior presença nos artigos que abordam jornalismo alternativo

\begin{tabular}{|c|c|}
\hline $\begin{array}{l}\text { Autores com maior presença nos estudos que tratam } \\
\text { de jornalismo alternativo }\end{array}$ & $\begin{array}{l}\text { Presença / } \\
\text { Citaçōes* }\end{array}$ \\
\hline $\begin{array}{l}\text { KUCINSKI, Bernardo. } \\
\text { Principal referência: Jornalistas e Revolucionários: } \\
\text { Nos tempos da imprensa alternativa. São Paulo: Ed. } \\
\text { Página Aberta Ltda., } 1991 .\end{array}$ & $18 / 19$ \\
\hline $\begin{array}{l}\text { PERUZZO, Cicilia M. K. } \\
\text { Principal referência: Aproximações entre a } \\
\text { comunicação popular e comunitária e a imprensa } \\
\text { alternativa na era do ciberespaço. Galáxia: São } \\
\text { Paulo, n. 17, jun/2009. }\end{array}$ & $11 / 18$ \\
\hline $\begin{array}{l}\text { CHINEM, Rivaldo. } \\
\text { Principal referência: Imprensa Alternativa: Jornalismo } \\
\text { de oposição e inovação. São Paulo: Ed. Ática, } 1995 .\end{array}$ & \\
\hline $\begin{array}{l}\text { DOWNING, John D. H. } \\
\text { Principal referência: Mídia radical: rebeldia nas } \\
\text { comunicações e movimentos sociais. São Paulo: } \\
\text { Senac, } 2002 \text {. }\end{array}$ & $6 / 7$ \\
\hline $\begin{array}{l}\text { FESTA, Regina; SILVA, Carlos E. L. (Orgs.). } \\
\text { Principal referência: Comunicação Popular e } \\
\text { Alternativa no Brasil. São Paulo: Ed. Paulinas, } 1986 .\end{array}$ & $6 / 7$ \\
\hline $\begin{array}{l}\text { MARCONDES FILHO, Ciro. } \\
\text { Principal referência: A saga dos cães perdidos. Série } \\
\text { Comunicação e Jornalismo. } 2 \text { a edição, São Paulo: } \\
\text { Hacker Editores Jornalismo, } 2002 .\end{array}$ & $5 / 8$ \\
\hline \multicolumn{2}{|c|}{$\begin{array}{l}\text { * Presença indica o número de artigos nos quais o/a autor/a } \\
\text { aparece. Citação indica o número de vezes que suas obras } \\
\text { aparecem. A diferença entre uma e outra reflete que mais obras } \\
\text { desse autor/a foram citadas. }\end{array}$} \\
\hline
\end{tabular}

Fonte: Elaboração dos autores.

abordada como sinônimo de "ativismo midiático", isto é, movimentos da sociedade, mais ou menos organizados, que buscam despertar na imprensa tradicional, mas não só nela, interesse e a consequente repercussão/divulgação de sua causa:"1 Outro grupo é o que faz um "uso alternativo das mídias tradicionais", como revistas ou programas de rádio, alterando

11 Sete estudos tratam da comunicação alternativa como ativismo midiático. 
o propósito, a linguagem e, muitas vezes, o formato, e retratam experiências que visam dar visibilidade a um segmento da sociedade, tanto interna quanto externamente a esse grupo; ${ }^{12}$

Há também os trabalhos que abordam o "uso convencional da comunicação", mas voltado para um grupo ou movimento social, o que Ihe daria status de alternativa. Em alguns casos, confunde-se com ações de relações públicas para esse grupo;13 $\bigcirc$ maior grupo é o que estuda o uso das "mídias alternativas às tradicionais" (alto-falante, cordel, rádios comunitárias etc.) para dar visibilidade ou buscar o reconhecimento de um grupo ou segmento da sociedade;14 Por fim, há o grupo dos pesquisadores que se propõem a fazer "reflexões teóricas" sobre a comunicação alternativa não-jornalística ${ }^{15}$. (ver Gráfico 2)

Gráfico 2 - Panorama das pesquisas sobre comunicação alternativa não-jornalística

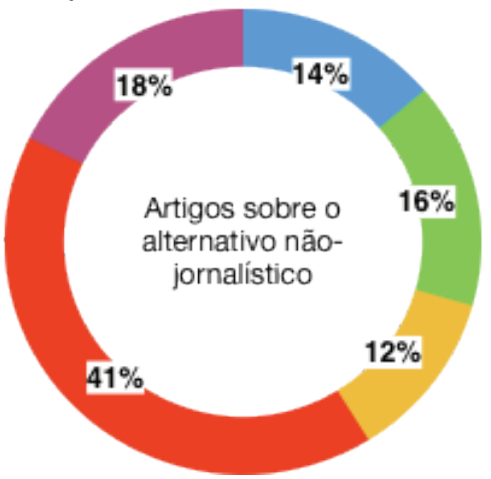
- Ativismo midiático Uso alternativo de midias tradicionais
Uso convencional para público alternativo
Midias alternativas
Pesquisas teóricas

Fonte: Elaboração dos autores.

\footnotetext{
12 Oito estudos tratam do uso alternativo de mídias tradicionais.

13 Seis estudos abordam o uso convencional das mídias, mas feitos por grupos específicos da sociedade.

14 O estudo de mídias alternativas às tradicionais foi feito em 21 trabalhos.

15 Nove trabalhos se dedicaram à reflexão teórica.
} 
Constatamos que há um predomínio de Cicilia Peruzzo, inclusive por conta de sua vasta produtividade. A sua principal obra referenciada, sendo citada em 23 textos, é Comunicação nos movimentos populares: a participação na construção da cidadania. Outros autores aparecem na sequência como John Downing com sua abordagem sobre mídia radical, citado 12 vezes em 11 trabalhos, e Maria da Glória Ghon que trabalha a teoria dos movimentos sociais, com 12 citações em nove trabalhos. Eles são seguidos por Regina Festa, Dênis de Moraes e Denise Cogo. (ver Tabela 2)

Tabela 2: Autores com maior presença em artigos que abordam comunicação alternativa não-jornalística

\begin{tabular}{|l|c|}
\hline \multicolumn{1}{|c|}{$\begin{array}{c}\text { Autores com maior presença nos estudos que } \\
\text { abordam comunicação alternativa não-jornalística }\end{array}$} & $\begin{array}{c}\text { Presença / } \\
\text { Citações * }\end{array}$ \\
\hline $\begin{array}{l}\text { PERUZZO, Cecilia Krohling. Comunicação nos } \\
\text { movimentos populares: a participação na construção } \\
\text { da cidadania. Rio Janeiro: Vozes. 1998. }\end{array}$ & 23 / 23 \\
\hline $\begin{array}{l}\text { DOWNING, John D. H. Mídia radical: rebeldia nas } \\
\text { comunicações e movimentos sociais. São Paulo: } \\
\text { Senac, 2002. }\end{array}$ & 11 / 12 \\
\hline $\begin{array}{l}\text { GOHN, Maria. G. Teoria dos movimentos sociais - } \\
\text { paradigmas clássicos e contemporâneos. 6a edição. } \\
\text { São Paulo, Loyola, 2007. }\end{array}$ & 9 / 12 \\
\hline $\begin{array}{l}\text { PERUZZO, Cicilia M. K. Direito à Comunicação } \\
\text { Comunitária, Partic ipação Popular e Cidadania. In: } \\
\text { OLIVEIRA; Maria José C. Comunicação Pública. São } \\
\text { Paulo, Alinca: 2004, p. 50-79. }\end{array}$ & 8 / 8 \\
\hline $\begin{array}{l}\text { FESTA, Regina; SILVA, Carlos E. L. (Orgs.). } \\
\text { Comunicação Popular e Alternativa no Brasil. São }\end{array}$ & 7 / 7 \\
Paulo: Ed. Paulinas, 1986. & 5 / 6 \\
\hline $\begin{array}{l}\text { MORAES, Denis. Comunicação, hegemonia e contra- } \\
\text { hegemonia: a contribuição teórica de Gramsci. Porto } \\
\text { Alegre: Revista Debates, v.4, n.1, 2010. }\end{array}$ & \\
\hline $\begin{array}{l}\text { COGO, Denise M. No ar uma rádio comunitária. São } \\
\text { Paulo: Paulinas, 1998. }\end{array}$ & 4 / 6 \\
\hline $\begin{array}{l}\text { * Presença indica o número de artigos nos quais o/a autor/a } \\
\text { aparece. Citação indica o número de vezes que suas obras } \\
\text { aparecem. A diferença entre uma e outra reflete que mais obras } \\
\text { desse autor/a foram citadas. Cicilia Peruzzo foi inserida duas vezes } \\
\text { devido ao volume de citações dessas obras. Ao todo ela aparece } \\
\text { como referência em 34 artigos com 78 citações. }\end{array}$ \\
\hline
\end{tabular}

Fonte: Elaboração dos autores. 
Segundo Otre (2015), juntamente com Regina Festa, Pedro Gilberto Gomes e Luiz Fernando Santoro, Cicilia Peruzzo torna-se uma das autoras-chave desde o início das pesquisas acadêmicas em comunicação popular, alternativa e comunitária.

\section{Principais referências teóricas}

Os autores mais citados nos trabalhos analisados compõem dois grupos distintos, para além da divisão entre alternativo jornalístico e não jornalístico: um que é mais referenciado quando se analisam diretamente os veículos que circularam durante o regime militar e no início da democratização no Brasil cujos representantes são autores como Bernardo Kucinski, Rivaldo Chinem e Perseu Abramo, ${ }^{16}$ e um segundo grupo que aborda o que se pode considerar a imprensa alternativa na contemporaneidade, que é representado especialmente por Cicilia Peruzzo, Denis de Moraes e John Downing.

Perseu Abramo (1988), inclusive, problematiza o sentido preciso da expressão "alternativa" quando aplicada à imprensa política que se fazia ou se tentava fazer durante o regime militar. Ancorado na primeira concepção de alternativo, que é algo "que ocorre com alternação ou alternância, que tem o efeito de substituir algo que vinha sendo feito, realizando determinada ação com função igual ou semelhante à que estava sendo feita originalmente, mas não simultaneamente", ele afirma que isso nunca, efetivamente, ocorreu no Brasil. Para ele, a imprensa política que se contrapunha ao regime militar nunca foi de fato

\footnotetext{
16 Apesar de ter mais citações que Perseu Abramo, Ciro Marcondes Filho não aborda diretamente a imprensa e/ou o jornalismo alternativo, aparecendo mais como um crítico à produção jornalística.
} 
uma alternativa à imprensa burguesa, "no sentido de oferecer ao leitor uma opção de leitura, do tipo que levaria um cidadão a deixar de ler o Jornal do Brasil para ler o Opinião, ou trocar O Estado de S. Paulo por Movimento" (ABRAMO, 1988, p. 1). Era preciso considerar outro aspecto, pois "tratava-se muito mais de fazer um contraponto à imprensa burguesa do que efetivamente substituí-la" (IDEM).

É uma visão diferente da apresentada por Rivaldo Chinem, que também se concentra no regime militar e descreve uma série de publicações que se impuseram nos anos 70, identificando-as como alternativas de noticiário, de postura, de mercado, de organização acionária à grande imprensa, não se restringindo apenas ao conteúdo editorial. Ele foca nos jornais políticos Pasquim, Opinião e Movimento falando da influência e luta desses periódicos. Para Chinem (1995, p. 8), "a imprensa alternativa fazia oposição sistemática ao regime militar, denunciava a tortura e a violação dos direitos humanos e criticava o modelo econômico" .

Bernardo Kucinski, com ênfase ao que ocorreu no período do regime militar, aborda as características de coragem da oposição ao regime e o contraste frente à complacência da grande imprensa. Em sua obra, ele apresenta as condições de existência da imprensa alternativa, aponta seus protagonistas e os arranjos entre eles e leitores, com a sociedade civil, com os partidos políticos e movimentos populares. Como Chinem, ele mostra que não era a resistência à ditadura a única razão da existência da imprensa alternativa. Deve-se considerar também os desejos da esquerda de protagonizar as transformações e dos jornalistas e intelectuais de terem espaços alternati- 
vos de veiculação de ideias, alternativos à grande imprensa e à universidade.

É preciso destacar que o jornalismo alternativo praticado no período de oposição à ditadura militar iniciada em 1964 se constitui como referência conceitual e em modelo de ação, que, de certa forma, molda as experiências posteriores. A resistência política, a insatisfação com o modelo da mídia hegemônica e a falta de espaço nessa mesma mídia para temas de interesse social, de certa forma, são elementos constitutivos da produção alternativa contemporânea.

Permeando esses conceitos todos está, como já frisamos, o de hegemonia que é apresentado nos artigos que se referenciam nos estudos de Denis de Moraes. Ele se interessa pelas intervenções em franca oposição à ideologia neoliberal sustentada pela mídia global e erigida sob dois pilares, o do consumo como instância máxima de organização societária e a liberação crescente e generalizada das atividades econômicas para incrementar a produtividade. Para Moraes (2010), a comunicação alternativa é a que atua como ferramenta para a comunicação no campo popular, considerando a militância social e com a tendência a democratizar a palavra e a informação. Além dos "veículos independentes do governo, do Estado e das corporações", o trabalho desenvolvido deve ser "dialógico e democratizador" e capaz de "difundir, co-produzir, organizar, articular, capacitar e reconstruir a memória, a identidade e a unidade na ação" (MORAES, 2007, p. 4), conceituação que o leva para além dos meios no jornalismo alternativo. Ele defende que é necessário "assumir visões transformadoras na relação com os leitores e a sociedade em geral, nos métodos de gestão, nas formas de fi- 
nanciamento e, sobretudo, na interpretação dos fatos sociais" (IDEM). Em Moraes, o jornalismo alternativo e a comunicação contra-hegemônica se confundem.

Cicília Maria Krohling Peruzzo, que é a autora mais citada nessa subárea da comunicação, amplia o conceito do jornalismo alternativo e o diferencia do que se compreende por comunicação alternativa, ao afirmar que o que caracteriza o jornalismo como alternativo é o fato de representar uma opção enquanto fonte de informação, tanto pelo conteúdo que oferece e quanto pelo tipo de abordagem realizada, fazendo uma ressalva a outras formas de comunicação alternativas, como carro de som e literatura de cordel. Com relação às mídias não jornalísticas, ela diz que "eram chamados alternativos pela força do sentido do seu conteúdo, porém, sem dispensar a leitura de jornais convencionais. Em suma, há uma comunicação alternativa no âmbito dos movimentos populares que extrapola jornais e o jornalismo" (PERUZZO, 2008).

A noção de uma categoria central para se pensar a comunicação alternativa está presente em seu trabalho, que detalha, em uma tentativa de taxonomia, uma proposta de organização categorial dessas experiências. Nesse sentido, ela vai distinguir a comunicação alternativa, popular e comunitária da imprensa alternativa, que

...trata-se de uma vertente que reúne processos de comunicação basicamente jornalísticos, que podem assumir feições mais amplas, de caráter autônomo e, por natureza, não alinhados aos padrões dos meios de comunicação convencionais, governos e demais setores que representam as classes dominantes. Os canais alternativos de maior porte se constituem em alternativa enquanto fontes de informações (PERUZZO, 2009, p. 140/141). 
Para definir as formas de expressão dessa imprensa, Peruzzo (2009) nos traz também os subgrupos jornalismo popular alternativo (de base popular), jornalismo alternativo colaborativo, jornalismo alternativo autônomo, jornalismo político-partidário e jornalismo sindical. O termo imprensa alternativa pretende ainda atualizar as experiências de oposição à ditadura militar notadamente investigadas por Kucinski (1991) e Chinem (1995), evidenciando uma continuidade na constituição de projetos jornalísticos transformadores.

Peruzzo consegue estabelecer uma ponte com o momento mais recente em que a comunicação alternativa se evidencia na contemporaneidade, fazendo uma aproximação com os conceitos defendidos por outros autores recentes como John Downing, que trata da comunicação realizada por grupos e movimentos com formatos alternativos, rebeldes, criativos e comunitários, buscando expandir o conceito de alternativo, abarcando todas as produções de movimentos que não se ligam ao que é dominante-hegemônico. Segundo Downing, em entrevista a Bona et al. (2015, p. 99), "a estrutura organizacional, o conteúdo, a estética, a linguagem, a entrada na comunidade, os modos de financiamento, são todos parte do 'alternativo'".

Para ele, a mídia radical seria "a mídia - em geral de pequena escala e sob muitas formas diferentes - que expressa uma visão alternativa às políticas, prioridades e perspectivas hegemônicas" (DOWNING, 2002, p. 21 ) sendo utilizada por grupos de oposição que pretendem transformar a sociedade. Ancorado em Gramsci, ${ }^{17}$ o autor enxerga a

17 Para Gramsci (2011), as pessoas que lutam pela transformação devem se engajar em uma "guerra de posição", ou seja, um processo de organização social e influência cultural que visa produzir um consenso articulado na sociedade civil, lugar de luta por hegemonia e também de sua manutenção. 
diversidade de expressões alternativas de comunicação como uma tentativa de construir processos de transformação, no sentido de combater a direção moral e intelectual vigente. Essa missão se atrela ao interesse dos movimentos sociais, dado o seu papel nessa mudança. As mídias são tanto suportes como instrumentos de propagação de ideias capazes de chacoalhar o status quo hegemônico, mesmo quando independentes de organizações.

Downing se refere tanto aos processos organizativos, passando pelos produtos e seu conteúdo significativo, generalizando no ponto de vista da política (ser contra-hegemônico) o eixo da síntese categorial. Os formatos e linguagens não são ignorados, mas evidenciados dentro da mesma universalidade fenomênica. Assim, por exemplo, uma charge, um radiojornal, uma peça teatral e um testemunho, mesmo em suas oceânicas distinções formais e diversidade produtiva, seriam unificados na ideia de uma ação cultural midiática contra-hegemônica.

\section{Cartografia do alternativo}

Para além da indicação das principais referências nas pesquisas que tratam do alternativo no jornalismo e na comunicação, também buscamos mapear a produção nacional nessa área, tendo por base o corpus selecionado. O que percebemos foi um amplo domínio da região Sudeste, em especial de São Paulo, com 1/3 de toda a produção nacional, seguido pela região Nordeste e depois pelo Sul. Entre as instituições mais produtivas se encontra a Universidade Metodista, com oito artigos e depois aparecem a Universidade Federal do Pará (UFPA) com sete, Universidade Federal do Rio Grande do Norte (UFRN) com seis e Universidade Federal do Ceará (UFCE) com cinco 
artigos contabilizados. ${ }^{18}$ Nota-se que há um grande predomínio de universidades públicas, em especial as federais, e que um número significativo de instituições (48) já teve trabalhos sobre o tema. (ver Gráfico 3)

Otre (2015) apontou também o Sudeste como a principal referência na área em termos de produção discente na pós-graduação demonstrando que, durante 40 anos, de 1972 a 2012, a Universidade Metodista, a USP e a UFRJ lideraram a elaboração de dissertações e teses com 26, 19 e 16 pesquisas, respectivamente.

Gráfico 3: Representação por estados da produção de artigos sobre jornalismo e comunicação alternativos.

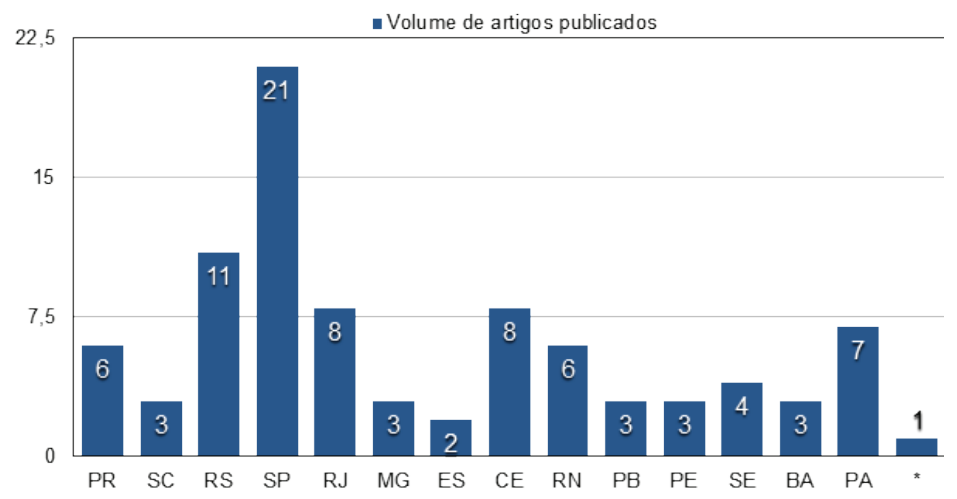

* DF, GO, MS, AL, RR e AM tiveram apenas um trabalho que foi incluído neste estudo.

Fonte: Elaboração dos autores.

18 Universidade Estadual Paulista (Unesp), Universidade Estadual de Ponta Grossa (UEPG) e Universidade de São Paulo (USP) registraram quatro artigos cada; Universidade Federal do Rio de Janeiro (UFRJ), Universidade Federal de Viçosa (UFV) e Universidade 9 de julho (UNINOVE) tiveram três publicações registradas. Nove outras instituições publicaram dois artigos e 29 publicaram apenas um. 


\section{O trabalho como categoria do alternativo}

Observamos que, apesar de haver uma consolidação nos modos de estudo do alternativo na comunicação, há um movimento inicial em desenvolvimento, em especial por membros do Centro de Pesquisas sobre Comunicação e Trabalho (CPCT), acerca do trabalho e do quanto aquilo que é alternativo no jornalismo influencia a atividade do jornalista. Esses autores não abordam o alternativo em termos de meios ou mensagens, emissores ou destinatários e não buscam analisar conteúdo ou formato.

O eixo principal de suas pesquisas diz respeito ao trabalho jornalístico e quais são as formas que esse trabalho se apresenta hoje, ou seja, busca-se definir, para além do emprego em redações, como é o mundo do trabalho dos jornalistas e o quanto isso influencia, define ou é influenciado e definido pelo alternativo. A pesquisa da qual este texto fez parte refere-se ao mundo do trabalho do jornalista em arranjos econômicos alternativos às corporações de mídia. Buscamos saber como é que se dá a atividade laboral quando não apenas o jornalismo, mas o trabalho jornalístico torna-se alternativo.

Acreditamos que o jornalismo alternativo esteja ligado umbilicalmente com um projeto de sociedade em que se precariza as relações de trabalho e se desvaloriza o trabalhador e o fazer jornalístico tradicional. Como é a classe dominante que tende a implantar a sua forma de ver o mundo, portanto a defesa da introdução de cada novo sistema de produção se referencia em um discurso de defesa do modelo atual de acumulação de capital. "As ideias da classe dominante são, em cada época, as ideias dominantes, isto é, a classe que é a força material 
dominante da sociedade é, ao mesmo tempo, sua força espiritual dominante" (MARX; ENGELS, 2007, p. 47). Oferecem-se novas formas de organização do trabalho, de regulação (ou desregulação) profissional e essa proposta de novo ordenamento social, a partir da flexibilização das relações de trabalho e do empreendedorismo, como a tábua de salvação do jornalismo e dos jornalistas.

Para se contrapor ao discurso hegemônico de desprezo com o trabalhador ou de fim do trabalho se faz necessário, como defende Figaro (2008), refletirmos sobre como o campo científico da comunicação se coloca para explicar a realidade desta sociedade em que vivemos e suas diversas formas de expressão.

\section{Considerações finais}

Nosso intuito com esta pesquisa sobre os conceitos em circulação nos estudos de jornalismo e comunicação alternativa no Brasil era produzir um mapeamento inicial que nos ajudasse a pensar no trabalho jornalístico em modelos alternativos em cenário de complexidade política, econômica e social, como é o caso brasileiro. A análise realizada nos levou a identificar definições variadas no uso desses conceitos.

A primeira diferença se refere à comunicação alternativa e ao jornalismo alternativo, que são tidos como objetos distintos. O jornalismo alternativo no Brasil é tratado na continuidade do que foi a experiência de oposição ao regime militar instaurado em 1964. A imprensa alternativa, marcada pela resistência política e pela presença de temas que não encontravam espaço na mídia tradicional, se constitui como ponto de partida e modelo para as análises no campo teórico. Na atualidade, o jornalismo alternativo se define 
pela abordagem de fatos não noticiados pela mídia tradicional, ou por trata-los de forma distinta da que é abordada por ela, e pelo posicionamento em contraposição ao discurso hegemônico.

A comunicação alternativa em geral é tratada como campo que não inclui necessariamente o jornalismo alternativo. Sua abordagem é mais ampla e se relaciona à exclusão social, de grupos ou visões de mundo e à promoção de temas e questões considerados relevantes para determinados grupos. Desse modo, a comunicação alternativa se vincula a movimentos sociais que buscam modificar a condição de invisibilidade a que estão sujeitos por um sistema dominante de comunicação. A preocupação destes estudos tem como foco o processo comunicacional e como ele integra o trabalho dos grupos e comunidades em defesa de seus interesses. A comunicação alternativa ganha assim o adjetivo "popular" ou "comunitária" em muitos trabalhos, que buscam compreender as especificidades da realidade brasileira.

Ao identificar que o jornalismo alternativo tem como características o contraponto ao discurso hegemônico e suas raízes na imprensa alternativa de oposição à ditadura, pudemos observar que as pesquisas buscam na história as características e os padrões para compreensão da atualidade. Distanciando-se da história do jornalismo alternativo, os estudiosos da comunicação alternativa, por sua vez, procuram compreendê-la em seus modos de produção e definir os conceitos a partir das transformações observadas na realidade. Ao ser retomada, a motivação inicial, que era justamente compreender o jornalismo alternativo a partir das suas lógicas produtivas, mais especificamente da categoria do trabalho, acreditamos ser 
possível observar que há apenas menções esparsas às rotinas produtivas, à inserção dos jornalistas nos processos comunicacionais ou mesmo às formas de sustentação econômica de tais iniciativas.

Tanto nas pesquisas acerca de comunicação alternativa quanto nas de jornalismo alternativo a ênfase recai sobre aspectos simbólicos ou sobre o processo comunicacional definido na esfera dos movimentos sociais e dos embates políticos. A pergunta que fazemos neste momento é: ao inserir a categoria trabalho na análise dessas práticas, podemos chegar a outra compreensão do que seja o alternativo na comunicação?

Acreditamos que as abordagens tanto sobre a comunicação alternativa quanto sobre o mundo do trabalho não podem ficar restritas aos pressupostos da razão instrumental e do pensamento hegemônico. É preciso demonstrar que o mundo se constitui também a partir do olhar dos trabalhadores, que no trabalho há espaço para outras linguagens, contradiscursos e movimentações que não obtêm visibilidade compatível com a sua importância. Disso decorre a importância de se dirigir o foco das pesquisas em comunicação para além dos meios, voltando-se para os comunicadores e os jornalistas, aqueles que lutam para se apresentar como sujeitos, lhes dando também o direito à palavra.

\section{Referências}

ABRAMO, P. Imprensa Alternativa: alcance e limites. Tempo e Presença, n. 233, agosto de 1988. Disponível em: http://novo.fpabramo. org.br/content/imprensa-alternativa-alcances-e-limites. Acesso em: 01/12/2016.

BARBOSA, A. Tarefas da imprensa alternativa na construção da contra-hegemonia na América Latina. In: XXXIV Congresso Brasileiro de Ciências da Comunicação, Recife, PE, 2011 
BONA, N.; CARVALHO, G. G.; RIBEIRO, A. T.; GIUVANUSI, R.; ANDRADE, J. e BECKER, D. Jornalismo alternativo e o ambiente digital: entrevista com John Downing. Revista UNINTER de Comunicação, v. 3, n. 5, p. 93-100, jul/dez. 2015.

CHINEM, R. Imprensa alternativa - Jornalismo de Oposição e inovação. São Paulo: Editora Ática, 1995.

DORNELLES, B. Divergências conceituais em torno da comunicação popular e comunitária na América Latina. E-Compós, v. 9, n. 11, 2007. Disponível em https://doi.org/10.30962/ec.176.

DOWNING, John. Mídia Radical: rebeldia nas comunicações e movimentos sociais. São Paulo: Senac, 2002.

FIGARO, R. Atividade de comunicação e trabalho. In: Revista TrabaIho, Educação e Saúde, v. 1. Rio de Janeiro, mar./2008.

Comunicação e Trabalho: binômio teórico produtivo para as pesquisas de recepção. In: Revista Mediaciones Sociales, v. 4. Madri-Espanha, 2009.

(Org.). As relações de comunicação e as condições de produção no trabalho de jornalistas em arranjos econômicos alternativos às corporações de mídia. São Paulo: ECA-USP, 2018.

KUNCINSKI, B. Jornalistas e revolucionários nos tempos da imprensa alternativa. São Paulo: Scritta, 1991.

MARX, Karl \& ENGELS, Fredrich. A ideologia alemã. São Paulo: Boitempo, 2007.

MORAES, D. Comunicação alternativa, redes virtuais e ativismo: avanços e dilemas. Economía Política de las Tecnologías de la Información y Comunicación, v. IX, n. 2, mayo/ago. 2007. Disponível em: http://seer.ufs.br/index.php/eptic/article/viewFile/226/224. Acesso em: 01/12/2016.

Comunicação, hegemonia e contra-hegemonia: A contribuição teórica de Gramsci. Debates, Porto Alegre/RS, v. 4, n. 1, p. 54-77, jan./jun. 2010.

OTRE, M. A. C. A Comunicação Popular, Alternativa e Comunitária inserida na Pós-graduação em Comunicação no Brasil (1972-2012). 
In: X Conferência Brasileira de Mídia Cidadã e V Conferência Sul-Americana de Mídia Cidadã, Unesp/Faac, Bauru, SP 2015.

PARENTE, R. E. Do midialivrismo de massa ao midialivrismo ciberativista: uma reflexão sobre as perspectivas de comunicação alternativa no Brasil. In: XXIII Encontro Anual da Compós, Belém, PA, 2014.

PERUZZO, M. C. K. Conceitos de comunicação popular, alternativa e comunitária revisitados. Reelaborações no setor. - Palabra Clave, v. 11 , n. 2 (2008).

Aproximações entre a comunicação popular e comunitária e a imprensa alternativa no Brasil na era do ciberespaço. Galáxia, 2009, junho: Disponível em: http://revistas.pucsp.br/index.php/galaxia/article/view/2108. Acesso em: 01/12/2016

POSSEBON, A. e NOGUEIRA, S. Comunicação e Cidadania: Diálogo Necessário. In: XXXIII Congresso Brasileiro de Ciências da Comunicação, Caxias do Sul, RS, 2010.

PRUDENCIO, K.; PUPO, F. V.; MENEZES, A. G. Uma alternativa ao jornalismo alternativo. In: XXXIII Congresso Brasileiro de Ciências da Comunicação, Caxias do Sul, RS 2010.

\section{FERNANDO FELÍCIO PACHI FILHO}

Jornalista, doutor em Linguística (UNICAMP), com pós-doutorado no Centro de Pesquisa em Comunicação e Trabalho da Escola de Comunicações e Artes (ECA/USP). É professor da Faculdade de Tecnologia Termomecânica (FTT) e da Universidade Paulista (UNIP).

\section{RAFAEL BELLAN RODRIGUES DE SOUZA}

Jornalista, doutor em Ciências Sociais pela Universidade Estadual Paulista Júlio de Mesquita Filho (UNESP), com pós-doutorado na Escola de Comunicações e Artes (ECA/USP). Professor do Departamento de Comunicação e do Programa de Pós-Graduação em Comunicação e Territorialidades da Universidade Federal do Espírito Santo (UFES).

\section{JOÃO AUGUSTO MOLIANI}

Jornalista, doutorando no PPGCOM da Escola de Comunicações e Artes (ECA/USP). É professor do Departamento de Comunicação e Linguagens da Universidade Tecnológica Federal do Paraná (UTFPR). 